\title{
REGULATION OF THE MULTILEVEL TRANSFER SYSTEM OF INNOVATIONS FOR SUSTAINABLE DEVELOPMENT
}

\author{
Olena SHKARUPA ${ }^{1}$, Ivan SHKARUPA ${ }^{2}$ \\ ${ }_{1,2}$ Sumy State University, Ukraine \\ Corresponding author's e-mail: elenashkarupa@econ.sumdu.edu.ua
}

\begin{abstract}
The abstract analyses provision of the regulatory issues of environmental modernization of the national economy. It presents new scientific approaches to the transfer system of innovations for sustainable development. It also focuses on principles and mechanism of transfer.
\end{abstract}

Keywords: innovation, indicators, reforms, economic instruments, sustainable development, national economy.

JEL Classification: O1, O3, P4

\section{INTRODUCTION}

Sustainable development is still an urgent issue as well as Ukraine and the Europe 2030 vision. The paper analyses the global experience of government stimulation of the transition to green economy growth, which shows that the levers of state regulation are effective when applied and targeted differently depending on the specifics of innovations and management. For example, in Germany, to stimulate the transition to eco-friendly transport, the levers of DR are differentiated by object and in a way: for companies and local communities investing in the construction of charging infrastructure for electric vehicles - government subsidies, and for citizens - grants to consumers (electric cars - 4 thousand euros, hybrid cars - 3 thousand euros).

\section{METHODOLOGY OF RESEARCH}

Niche eco-innovations are defined as the basic object of the transfer - narrowly specialized segmental object-process eco-innovations in individual functional units of the economic system, which, through their scaling, geographical and sectoral diversification, become catalysts for green economy growth. Unlike other forms of transfer, they have the following features:

1) dual (object-process) nature - their simultaneous understanding, on the one hand, as an object of modernization (specific technology, technology, product), and on the other - as a process (complex of organizational and management measures);

2) the ability to cumulative accumulation, triggering a chain reaction, in the process of which changes the target of innovation and widens the circle of final beneficiaries. Niche eco-innovations at the level of individual households, companies and institutions are aimed at solving a specific pragmatic business problem (changing the level of material, energy, resource consumption of production and / or consumption). With their scaling, geographical and sectoral diversification, the potential for their impact on economic development 
increases (carbon productivity increases, GDP per unit of energy consumption increases and other indicators of green growth of the national economy) become beneficiaries of this entities that have introduced niche eco-modernization, and a much wider range of stakeholders (local communities, territorial communities, government organizations, investors, society at large).

For diversification of forms, methods and levers of state regulation of transfer of innovations we are offered to allocate the following kinds of niche eco-innovations:

1) resource-optimizing (to increase efficiency of resource use, energy consumption, etc.);

2) information (to improve the efficiency of management accounting and control the role of data);

3) technical and technological (for updating technologies, facilities, projects, programs, etc.);

4) consumer-oriented (to influence consumer expectations);

5) institutional and legal (to improve the system of standards, regulations, directives).

The formation of an innovation transfer system requires its adjustment to its principles, which are proposed to be divided into general and specific ones. The system of general principles is proposed to be supplemented by the following specific principles:

1) the principle of network-centricity (based on the functional peculiarities of different types of niche innovations, for their scaling at the economy level. The system of collecting and processing the statistical information in the system of state regulation should be built on the principle of network-centricity);

2) the principle of conjunction (compliance of the quality of the implemented niche ecoinnovations with their resource provision);

3 ) the principle of extended coordination (to coordinate the vector of regulation of the transfer of innovations and the choice of specific regulatory measures, it is necessary to form a targeting system, which should balance both the quantity and quality of niche ecoinnovations);

4) the principle of inclusion (the key to the effectiveness of state regulation of innovation transfer is the communication involvement of all stakeholders in this process).

In the context of the implementation of the proposed system of state regulation of innovation transfer, it is important to assess and take into account the overall level of innovation activity in the country, as well as the willingness of entrepreneurs to further scale up eco-modernization.

\section{FINDINGS / RESULTS}

It is advisable to emphasize that the macro level is the level of the national horizon for introducing innovations, where social culture, values are formed, "rules of the game" are established in the market, society's culture is formed, social values are realized and the benefits of a recycling economy are realized.

From a theoretical point of view, niche eco-innovatization forms a model of multi-level growth of economic potential of national economy, which, in our opinion, is quite 
appropriate and flexibly reflects the structure of multilevel transfer system and allows to determine how it can influence the welfare of the country. It is advisable to emphasize that the macro level is the level of the national implementation of the multilevel transfer of ecoinnovations, where public culture, values are set, "rules of the game" are formed on the market, the society's culture, social values and benefits are realized. The meso-level includes the dominant infrastructure and the existing level of technology, economic and institutional formats, regulatory policies in the region, which are formed under the influence of the global market, as well as current political and economic institutions and the legal framework (these factors together form the modern socio-economic system).

Micro-level, or directly "niche", is an arena, where environmentally significant modernization shifts that create advantages of recirculating economy and "green" growth of the economy.

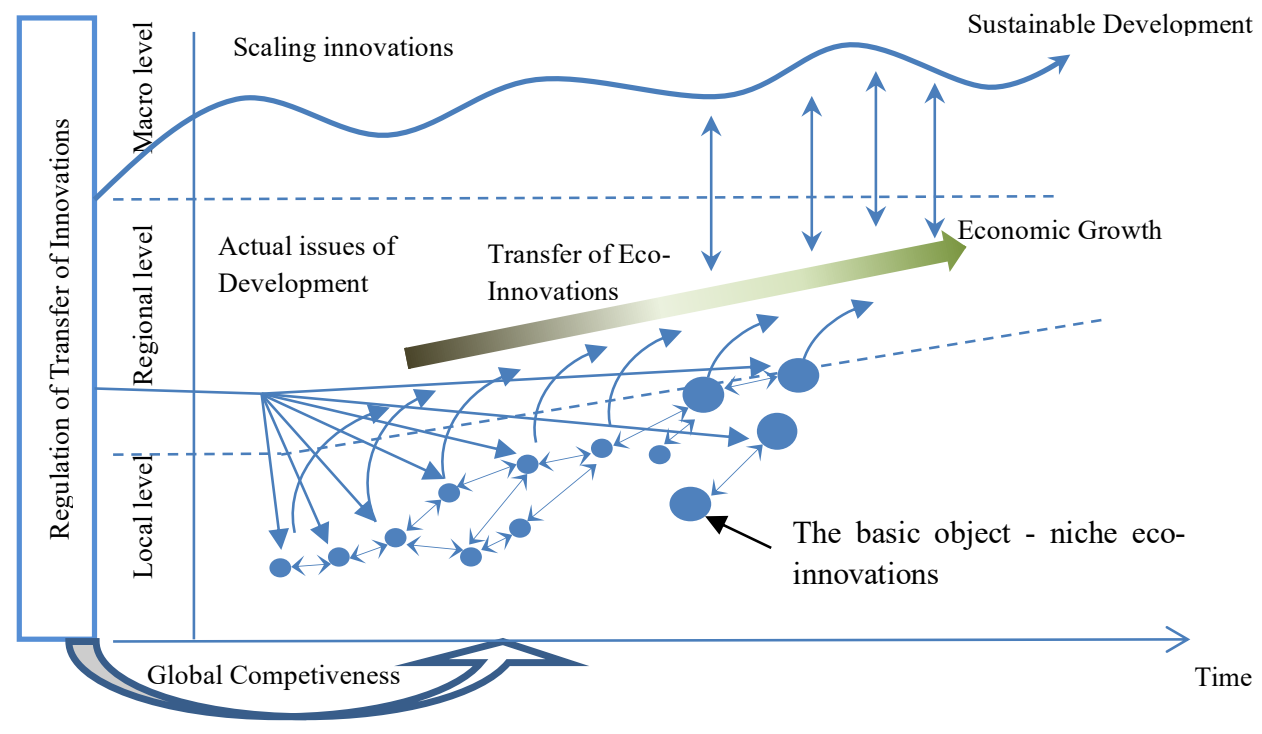

Fig. 1. Multi-level innovation transfers scheme (authors)

These are the basic objects where the new economy plan is formed (implementation of more effective technologies, innovative models, business development, political and public institutions, etc.). Interaction between the three levels of the system will determine the emergence (or not) of a system transition to new socio-economic relations.

Regional includes the dominant infrastructure and the available level of technology, economic and institutional formats, regulatory policies in the region, which are formed under the influence of the global market, as well as current political and economic institutions and the legal framework (these factors together constitute the current socio-economic system). The local level is an arena where environmentally significant modernization shifts are being implemented, creating the benefits of a recycling economy and green economy growth. These are the basic facilities where the plan of the new economy is formed (the introduction of more efficient technologies, innovative models, business development, political and public institutions, etc.).

Thus, for providing ecological modernization due to improvement of the normativelegal sphere of Ukraine it is necessary to not less than 900 Euro per capita. Assessing these indicators, it should be borne in mind that the relevant costs of the experts are for a period 
of 10-12 to 20 years. According to the analysis, it is clear that resource needs for the introduction of modernization changes are very significant, especially critical in the conditions of management. In addition to these estimates of the investment cost of implementation of environmental legislation, there are other hypothetical estimates in Ukraine. They are in the range of 50-100 billion. and demonstrating burdensome environmental commitments.

In our opinion, transfer of innovations "from above" is a more "fashionable", political process, the desire of the government to demonstrate accelerated development of the economy and public relations, but more often this modernization mechanism is built in such a way that it does not contribute to development processes. The result is that there is a paradox between the nature of innovation processes that naturally develop "from below". Business independently finds directions, resources and potential for renewal and a state that tries to "keep them in a safe and extremely profitable way". Transfer of innovations "from below" is a livelier process necessary for the activities of enterprises, and it is developing contrary to the administrative, institutional, and economic risks inherent in the economy.

\section{CONCLUSIONS}

We believe that the multilevel transfer of innovations within the framework of strategic orientation for sustainable development provides the use of the instruments of state regulation; the formation of a national innovation system on the formulated principles of settling the relations of the stakeholders of innovation activity.

\section{ACKNOWLEDGMENT}

It contains the results of research carried out within the framework of research work that is financed of the Ministry of Education and Science of Ukraine "Modelling the transfer of eco-innovations in the system "enterprise-region-state": the impact on economic growth and security of Ukraine", (№0119U100364).

\section{REFERENCES}

Aurik, J., \& Leurent, H. (2018). Which countries are best prepared for the future of production? Retrieved from https://www.weforum.org/agenda/2018/01/time-for-action-who-is-really-ready-for-the-future-ofproduction/

Klump, R. (2015). Economic Policy. Instruments, aims and Institutions, third revised edition. Georgian translation. Publishing house of TSU, Tbilisi;

Eurostat. (2018a). Research and development expenditures within the European Union. Retrieved from: http://ec.europa.eu/eurostat/statistics-explained/index.php/R_\%26_D_expenditure

Eurostat. (2018b). European Innovation Scoreboard $2018 . \quad$ Retrieved from: http://ec.europa.eu/growth/industry/innovation/facts-figures/scoreboards_en 